\title{
Long-Term Results and Follow-Up Examinations after Endovascular Embolization for Unruptured Cerebral Aneurysms
}

\author{
(D) T. Murakami, (D). Nishida, (D). Asai, (D) Y. Kadono, DH. Nakamura, (D). Fujinaka, and (D) H. Kishima
}

\begin{abstract}
BACKGROUND AND PURPOSE: The appropriate period of follow-up examinations after endovascular embolization for cerebral aneurysms using time-of-flight MR angiography is not well-known. We retrospectively investigated long-term results after endovascular embolization for unruptured cerebral aneurysms and evaluated the periods from embolization to recanalization and retreatment.
\end{abstract}

MATERIALS AND METHODS: Between April 2006 and March 2011, one hundred forty-eight unruptured aneurysms were treated with endovascular coil embolization. Among them, we investigated 116 unruptured aneurysms, which were followed up for $>5$ years. Time-offlight MR angiography was performed at 1 day, 3-6 months, 1 year after the procedure, and every year thereafter.

RESULTS: The mean follow-up period was $7.0 \pm 1.4$ years. Recanalization was observed in 19 (16.3\%) aneurysms within 2 years. Among them, retreatment for recanalization was performed in $8(6.8 \%)$ aneurysms. No recanalization was detected in any aneurysms that had been stable in the first 2 years after embolization. A larger maximum aneurysm size was significantly correlated with recanalization $(P=.019)$.

CONCLUSIONS: Aneurysms in which recanalization was not observed within 2 years after endovascular coil embolization were stable during a mean follow-up of 7 years. This result may be helpful in considering the appropriate span or frequency of follow-up imaging for embolized cerebral aneurysms.

ABBREVIATIONS: $\mathrm{BA}=$ basilar artery; $\mathrm{CO}=$ complete obliteration; $\mathrm{RA}=$ residual aneurysm; $\mathrm{RN}=$ residual neck

$\mathbf{E}$ ndovascular coil embolization is one of the standard treatments for unruptured cerebral aneurysms. ${ }^{1}$ A follow-up imaging study after embolization is crucial because the recanalization rate is $4.7 \%-33.6 \%$ and the retreatment rate is $4.7 \%-$ $17.4 \% .^{2-10}$ Although DSA is the criterion standard for follow-up imaging studies, TOF-MRA is also an accurate method for detecting recanalization in cerebral aneurysms treated with coil embolization. ${ }^{11}$ However, the appropriate span or frequency of follow-up imaging for embolized cerebral aneurysms using TOF-MRA is not well-known. Therefore, we retrospectively investigated long-term results after embolization for unruptured cerebral aneurysms and evaluated the periods from embolization to recanalization and retreatment to optimize follow-up examinations.

Received March 19, 2019; accepted after revision May 13.

From the Department of Neurosurgery (T.M., T.N., K.A., Y.K., H.N., H.K.), Osaka University Graduate School of Medicine, Osaka, Japan; Department of Neurosurgery (T.F.), Osaka National Hospital, Osaka, Japan; and Department of Neurosurgery (T.M.), Osaka Neurological Institute, Osaka, Japan.

Please address correspondence to Hajime Nakamura, Department of Neurosurgery, Osaka University Graduate School of Medicine, 2-2 Yamadaoka, Suita, Osaka 565-0871, Japan; e-mail: hajime@nsurg.med.osaka-u.ac.jp

http://dx.doi.org/10.3174/ajnr.A6101

\section{MATERIALS AND METHODS}

\section{Ethics}

Ethics approval for the study was obtained from the Osaka University Hospital institutional review board (approval No. 16490).

\section{Patient Population and Follow-Up Periods}

In our institution, the treatment indication for unruptured cerebral aneurysms was decided according to the Japanese Guidelines for the Management of Stroke. ${ }^{12}$ Endovascular coil embolization or surgical neck clipping was performed with the patient's informed consent. Endovascular coil embolization was selected in any aneurysm, except in those in which embolization was not applicable. In case of multiple aneurysms, coil embolization was also performed for any aneurysm, even if it was small, when it was technically possible. Between April 2006 and March 2011, one hundred forty-eight unruptured aneurysms in 126 patients were treated with endovascular coil embolization at Osaka University Hospital. Among the 148 unruptured aneurysms, 30 unruptured aneurysms in 27 patients could not be followed up for $>5$ years because patients had stopped coming to the hospital (non-follow-up group). There were also 3 cases of cerebral dissecting aneurysms. Among them, 2 cases were excluded because parent artery occlusion had been performed. Therefore, we assessed 116 


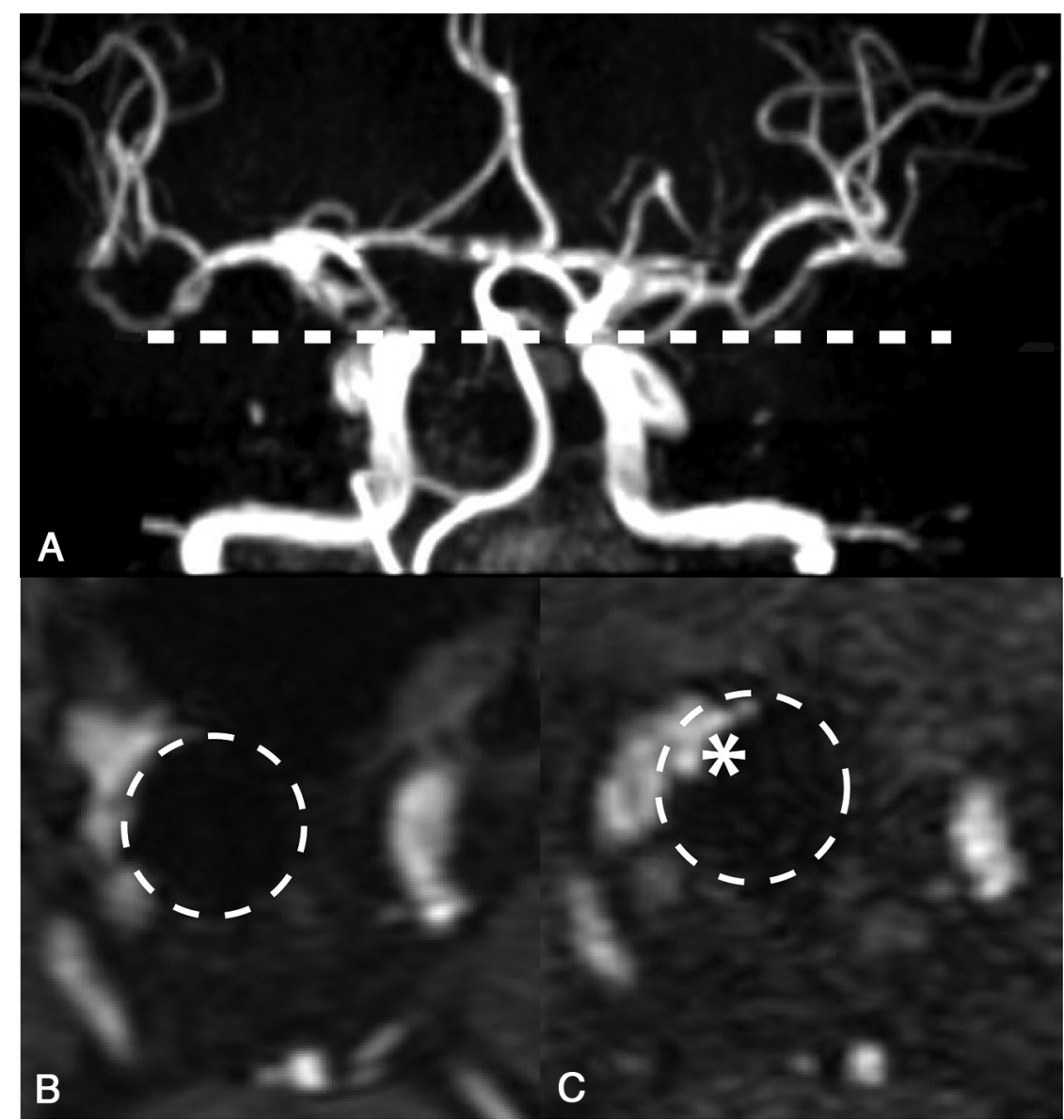

FIG 1. Evaluation of recanalization with MRA and TOF-MRA. A, At postprocedural day 1, we routinely evaluate the status of occlusion using MR angiography. The dotted line shows a cross-section of $B$ and $C$. B, A residual neck is observed in the right internal carotid artery aneurysm after coil embolization at postprocedural day 1. Dotted circles show a coil mass. C, Blood flow signal of the residual neck has increased (asterisk) at 1 year after endovascular embolization compared with postprocedural day 1. This increased blood flow signal is regarded as recanalization.

unruptured aneurysms in 97 patients who were followed up for $>5$ years (follow-up group). The last follow-up data were collected in January 2017.

\section{Aneurysm Measurement and Location}

We measured the maximum size of aneurysms with $3 \mathrm{D}$ rotational angiography before treatment. We defined the bifurcation or nonbifurcation type of aneurysm as follows: The bifurcation type included all aneurysms that were located at an arterial bifurcation, such as the middle cerebral artery, anterior communicating artery, distal anterior cerebral artery, posterior communicating artery, ophthalmic artery, anterior choroidal artery, posterior inferior cerebellar artery, anterior inferior cerebellar artery and superior cerebellar artery, the top of the internal carotid artery, and the top of the basilar artery (BA). The nonbifurcation type of aneurysm was located at the arterial trunk, such as aneurysms at the dorsal wall of the internal carotid artery and BA trunk.

\section{Endovascular Coil Embolization Procedure}

Each endovascular embolization for an unruptured aneurysm was performed between April 2006 and March 2011 by a neurosurgeon who specialized in neurointervention (T.F.) To avoid ischemic complications, we administered double antiplatelet drugs (aspirin, $100 \mathrm{mg}$, + clopidogrel, 75 $\mathrm{mg}$, or aspirin, $100 \mathrm{mg},+$ cilostazol, $200 \mathrm{mg}$ ) 1 week before endovascular coil embolization. Double antiplatelet drugs were continued for 1-6 months after the procedure. A single antiplatelet drug was then continued for 6 months in patients without an assisting or for life in patients with a stent. An intravenous bolus injection of heparin was provided after arterial sheath insertion to maintain the activated clotting time at 250-300 seconds. Assisting devices, including balloons and stents, were selected according to the morphology and size of the neck and dome of the aneurysm. After a microcatheter was navigated into the aneurysm, platinum coils were placed in the aneurysm as long as the microcatheter was not pushed out of the aneurysm.

\section{Angiographic Results and Follow-Up Evaluation}

The immediate postprocedural angiographic results were classified using the Raymond-Roy occlusion classification ${ }^{13}$ by a neurosurgeon (T.F.) as follows: complete obliteration (CO), residual neck (RN), and residual aneurysm (RA). TOF-MRA was performed at 1 day, 3-6 months, 1 year after treatment, and every year thereafter. DSA at 1 year was also routinely performed for monitoring embolized aneurysms. "Recanalization" was defined as an increasing blood flow signal in the aneurysm using TOF-MRA compared with a previous image (Fig 1). MR imaging was performed using either a $1.5 \mathrm{~T}$ system (Ingenia; Philips Healthcare, Best, the Netherlands), or a 3T system (Discovery MR750 and MR750w; GE Healthcare, Milwaukee, Wisconsin, or Achieva; Philips Healthcare). Recanalization was judged by other neurosurgeons (H.N., T.N., and T.M.). These evaluations were performed independently and blindly. When there was a discrepancy, a decision was made by discussion with different neurosurgeons (K.A. and Y.K.). All neurosurgeons were board-certified as recorded by the Japan Neurosurgical Society. Therefore, they were well-informed regarding TOF-MRA technique properties, skills, artifacts, and limitations. These neurosurgeons were also experts in evaluating recanalization because they specialized in neurointervention. Furthermore, all neurosurgeons who evaluated recanalization were not involved in treating the cases of endovascular coil embolization. Retreatment was performed if the recanalization space was large enough for retreatment or it became larger or neurologic symptoms appeared. 
Table 1: Analysis of recanalization after endovascular embolization of unruptured aneurysms

\begin{tabular}{lcccc}
\multicolumn{1}{c}{ Parameters } & $\begin{array}{c}\text { Recanalization } \\
(\boldsymbol{n}=\mathbf{1 9})\end{array}$ & $\begin{array}{c}\text { Nonrecanalization } \\
(\boldsymbol{n}=\mathbf{9 7})\end{array}$ & $\begin{array}{c}\text { Total or } \\
\text { Mean Value }\end{array}$ & $\begin{array}{c}\boldsymbol{P} \\
\text { Value }\end{array}$ \\
\hline Age (mean) (yr) & $57.9 \pm 12.1$ & $59.6 \pm 11.4$ & $59.8 \pm 11.3$ & $.55^{\mathrm{a}}$ \\
Sex (male/female) & $3: 16$ & $31: 66$ & $34: 82$ & $.18^{\mathrm{b}}$ \\
Location of the aneurysm (No.) & & & & $.72^{\mathrm{b}}$ \\
$\quad$ MCA & 1 & 10 & 11 & \\
PcomA & 1 & 7 & 8 & \\
ICA & 12 & 50 & 62 & $.019^{\mathrm{a}}$ \\
BA tip & 3 & 6 & 26 & $.15^{\mathrm{b}}$ \\
Others & 2 & 24 & 7.1 & $.34^{\mathrm{b}}$ \\
Size of the aneurysm (No.) (mm) & 9 & 6.8 & 86 \\
Balloon-assisted (No.) & 17 & 69 & 8 & $.34^{\mathrm{b}}$ \\
Stent-assisted (No.) & 0 & 8 & $62 / 45 / 9$ \\
CO/RN/RA (No.) & $9 / 7 / 3$ & $53 / 38 / 6$ & $(53 \% / 38 \% / 7.7 \%)$ & \\
\hline
\end{tabular}

Note:-PcomA indicates posterior communicating artery

a $T$ test.

${ }^{\mathrm{b}}$ Fisher exact test.

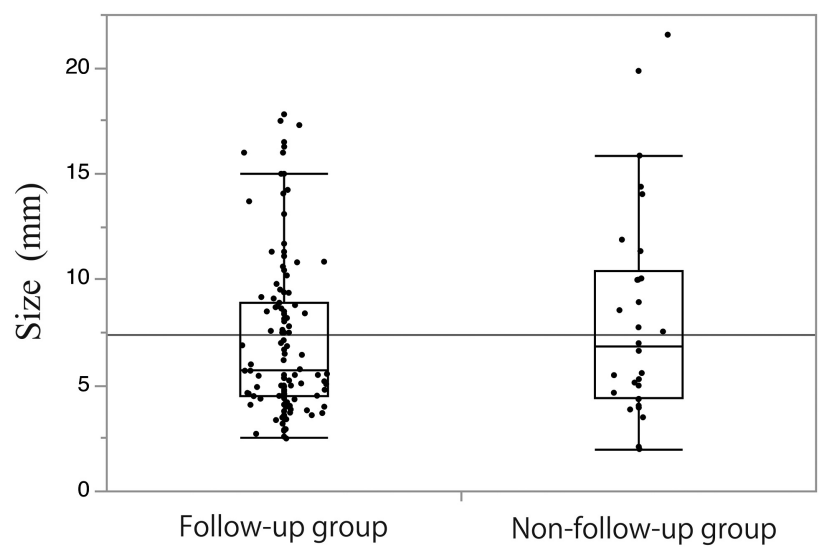

FIG 2. Comparison of the maximum size of aneurysms between the follow-up and non-follow-up groups. A total of 116 unruptured aneurysms were followed up for $>5$ years. These aneurysms were categorized as the follow-up-group. Thirty unruptured aneurysms could not be followed up for $>5$ years. These aneurysms were categorized as the non-follow-up group. The distribution of the maximum size of aneurysms between the follow-up and non-follow-up groups was not significantly different $(P=.24$, Student $t$ test).

\section{Statistical Analysis}

Statistical analysis was performed with statistical software (JMP Pro 14.0.0; SAS Institute, Cary, North Carolina). Mean and frequency comparisons were analyzed simply. The nonrecanalized rate of embolized aneurysms was analyzed using the Kaplan-Meier method. The Bonferroni method was used for multiple comparisons. The relationships between recanalization and age, sex, initial angiographic results, aneurysm size, aneurysm site, and adjunctive technique (using balloon devices and stents) were also analyzed with the Student $t$ test and Fisher exact test. Multivariable logistic regression was used for multivariate analysis. Differences were considered significant at $P<.05$.

\section{RESULTS}

\section{Patients' Background and Details of Aneurysms}

We investigated 116 unruptured aneurysms in 97 patients who were followed up for $>5$ years. The mean age of the patients was $59.8 \pm 11.3$ years, and $82(70.6 \%)$ were women. Among the 116 aneurysms, $94(81.0 \%)$ were located in the anterior circulation and $22(19.0 \%)$ were in the posterior circulation. Common aneurysmal locations are shown in Table 1. Fifty-eight (50.0\%) aneurysms were the bifurcation type, and 58 (50.0\%) were the nonbifurcation type. There was 1 case of a dissecting ICA aneurysm, which was categorized as a nonbifurcation-type aneurysm. The maximum diameter of aneurysms was measured on an angiogram, and the mean maximum size of aneurysms was $7.1 \pm 3.7 \mathrm{~mm}$. The distribution of the maximum size of each aneurysm was not significantly different between the follow-up and non-follow-up groups $(P=.24$, Fig 2$)$. Furthermore, among the 97 patients, $33(34.0 \%)$ patients had multiple aneurysms including untreated ones because of the small size. The mean number of aneurysms, including untreated aneurysms, was $1.4 \pm 0.8$ (range, 1-6).

\section{Initial Angiographic Results and Recanalization}

Endovascular procedures were performed with the patient under local anesthesia in $114(98.2 \%)$ cases and under general anesthesia in $2(1.8 \%)$ cases. In an immediate postprocedural angiogram, $\mathrm{CO}$, an RN, and an RA were observed in 62 (53.4\%), 45 (38.7\%), and $9(7.7 \%)$ aneurysms, respectively.

In our study, the mean follow-up period was $7.0 \pm 1.4$ years. In 116 unruptured aneurysms, recanalization was observed in 19 (16.3\%). Three expert neurosurgeons (H.N., T.N., and T.M.) were in agreement regarding these results. There was 1 case of symptomatic recurrence $(1 / 19,5 \%)$, which was a visual disorder. Retreatment for recanalization was performed in $8(6.8 \%)$ aneurysms. Among them, $3(2.5 \%)$ aneurysms were retreated after $>5$ years from initial embolization. For all the retreated aneurysms, the 3 expert neurosurgeons were in agreement regarding the evaluation of the appearance of aneurysms on subsequent DSA. Figure 3 shows the Kaplan-Meier method for the nonrecanalization rate of the treated aneurysms with time. Aneurysms in which recanalization was not observed within 2 years after the procedure were not recanalized after this time.

\section{Factors Associated with Recanalization}

In univariate analysis, the maximum size of the aneurysm was significantly correlated with the recanalization rate $(P=.019$, Fig 4$)$. Age $(P=.55), \operatorname{sex}(P=.18)$, and the location of the aneurysm $(P=.72)$ were not significantly correlated with recanalization (Table 1$)$. The immediate postprocedural angiographic results were not significantly related to recanalization $(P=.34)$. Multivariable logistic regression also showed that only the maximum size of the aneurysm was significantly correlated with the recanalization rate (odds ratio $=$ 1.24; $95 \%$ confidence interval, $1.05-1.43 ; P=.006$; Table 2). There was no aneurysmal rupture in the follow-up period.

\section{Relationship between the Size of the Aneurysm and the Nonrecanalization Rate}

We stratified aneurysms into 3 groups $(<5 \mathrm{~mm}, 5-10 \mathrm{~mm},>10$ $\mathrm{mm}$ ) according to their dome size. The number of aneurysms 


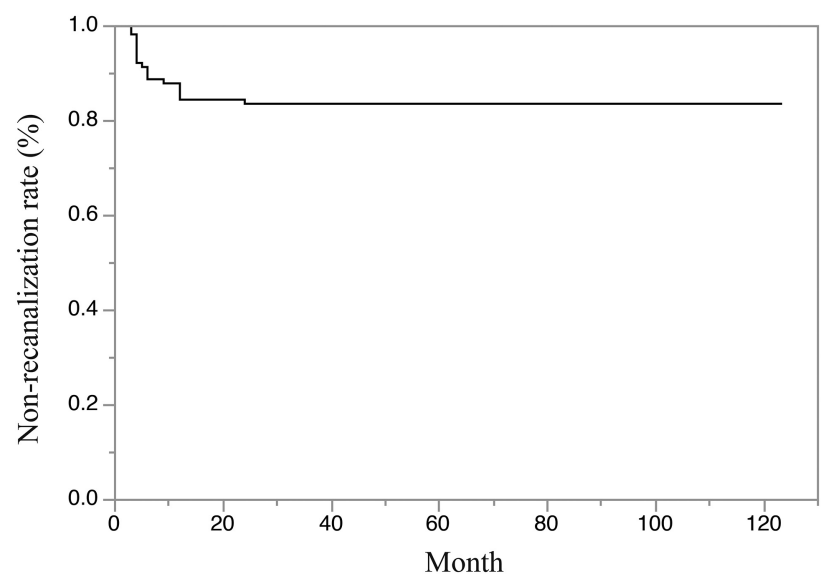

FIG 3. Kaplan-Meier analysis of the nonrecanalization rate. The nonrecanalization rate of embolized aneurysms was decreased by 2 years, and there was no recanalization after this time.

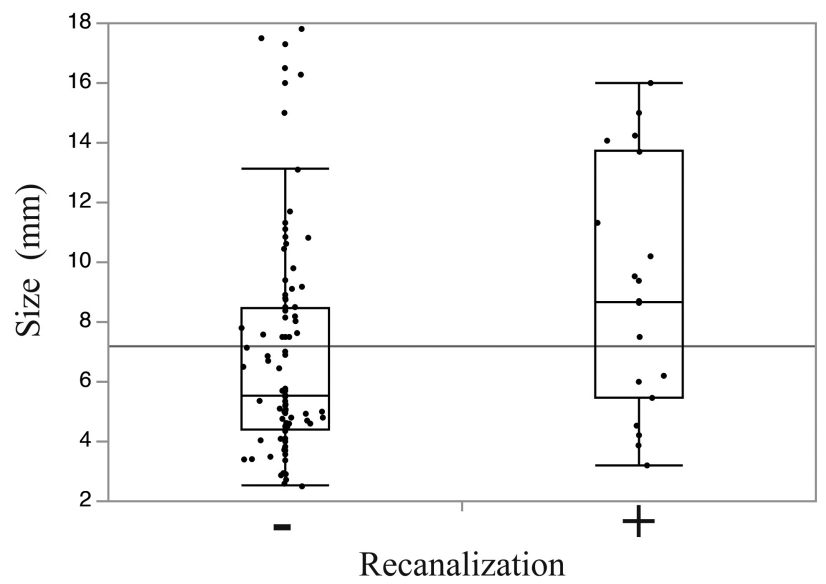

FIG 4. Correlation between recanalization and the size of aneurysms. The maximum size of aneurysms was significantly correlated with the recanalization rate $(P=.019$, Student $t$ test).

Table 2: Multivariable logistic regression for recanalization

\begin{tabular}{lclc}
\hline \multicolumn{1}{c}{ Variable } & OR & \multicolumn{1}{c}{$95 \% \mathrm{Cl}$} & $\boldsymbol{P}$ Value \\
\hline Age & 0.99 & $0.95-1.04$ & .97 \\
Sex & 1.35 & $0.29-6.12$ & .69 \\
Anterior/posterior & 3.19 & $0.46-22.23$ & .22 \\
Bifurcation type/nonbifurcation & 1.08 & $0.25-4.56$ & .91 \\
$\quad$ type & & & \\
Aneurysm location (ICA) & 1.94 & $0.24-15.42$ & .52 \\
Size (mm) & 1.24 & $1.05-1.43$ & .006 \\
No. of aneurysms & 1.33 & $0.80-2.21$ & .27 \\
Balloon-assisted & 4.04 & $0.71-22.97$ & .084 \\
Stent-assisted & 0 & 0 & .07 \\
CO/RN/RA & 1.05 & $0.38-2.86$ & .91 \\
Follow-up period & 1 & $0.99-1.00$ & .34 \\
\hline
\end{tabular}

in these 3 groups was 44,50, and 22, respectively. The nonrecanalization rate of embolized aneurysms in these 3 groups using the Kaplan-Meier method is shown in Fig 5. The group of aneurysms of $>10 \mathrm{~mm}$ showed a significantly higher recanalization rate within 2 years compared with $<5 \mathrm{~mm}(P=.021$, Bonferroni method). Despite the size of the aneurysms, those in which recanalization was not observed within 2 years after the procedure were not recanalized during the follow-up period (Fig 5).

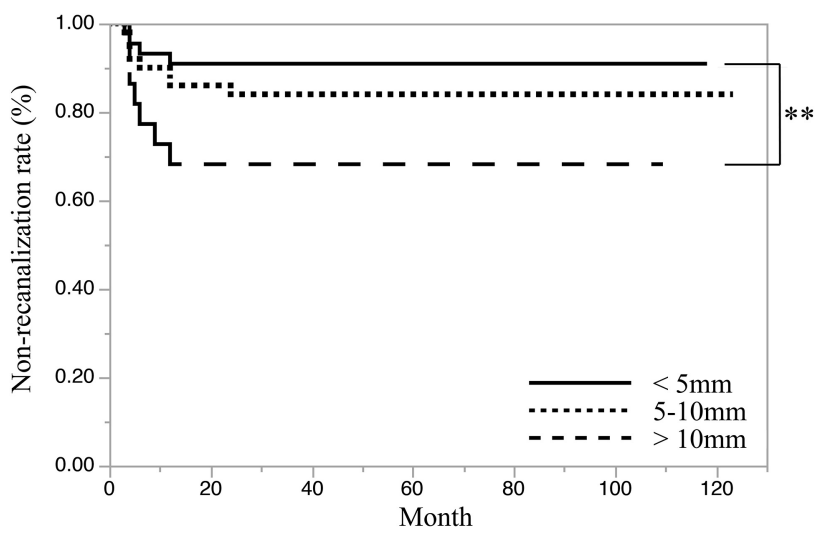

FIG 5. The relationship between the size of aneurysms and the nonrecanalization rate using the Kaplan-Meier method. Aneurysms were divided into $<5-\mathrm{mm}$, 5- to $10-\mathrm{mm}$, and $>10-\mathrm{mm}$ groups. Using the Kaplan-Meier method, we analyzed the relationship between time (months) and the nonrecanalization rate of treated aneurysms in each group. The thick line indicates the nonrecanalization rate of the $<5$-mm group. The dotted line indicates the $5-$ to $10-\mathrm{mm}$ group. The dashed line indicates the $>10-\mathrm{mm}$ group. The Bonferroni method showed that the $>10-\mathrm{mm}$ group had a significantly higher recanalization rate within 2 years compared with the $<5-\mathrm{mm}$ group. Despite the size of the aneurysms, aneurysms in which recanalization was not observed within 2 years after the procedure were not recanalized after this time. Double asterisks indicate $P=.021$.

\section{DISCUSSION}

Our study showed that the maximum size of aneurysms was significantly correlated with the recanalization rate. However, despite aneurysmal size, aneurysms in which recanalization was not observed within 2 years after endovascular coil embolization were stable during the follow-up period.

Endovascular coil embolization is accepted as a standard therapy for cerebral aneurysms worldwide. ${ }^{1}$ Recanalization is one of the major concerns of endovascular coil embolization for cerebral aneurysms. Our study showed that recanalization and retreatment rates of embolized aneurysms were $16.3 \%$ and $6.8 \%$, respectively, which are consistent with previous reports (recanalization rate: $4.7 \%-33.6 \%$; retreatment rate: $4.7 \%-17.4 \%) .{ }^{2-10}$ A previous study reported that risk factors for recanalization were a ruptured aneurysm, ${ }^{4}$ a wide neck, ${ }^{3}$ a larger size,,${ }^{3,9,14-16}$ incomplete occlusion, ${ }^{9,17}$ a low-volume embolization rate, ${ }^{15,18,19}$ and a posterior circulation aneurysm. ${ }^{20}$ In our study, a larger maximum size of the aneurysm was also significantly correlated with recanalization in univariate and multivariate analyses.

Incomplete occlusion, such as an $\mathrm{RN}$ and $\mathrm{RA}$ at the initial procedure, was not associated with recanalization in the present study. A previous report showed that coils in the acute phase facilitated coil-thrombus formation in the aneurysm, and this prevented inflow of blood. ${ }^{21}$ A coil-thrombus complex might have resulted in an increase in the volume-packing ratio and cases of CO, though tiny spaces between coils may actually exist. Therefore, the Raymond-Roy occlusion classification in the acute phase might have been inaccurate.

The recanalization rates of posterior circulation aneurysms and BA aneurysms are higher than those of aneurysms in other locations. ${ }^{20}$ Although the recanalization rate of BA aneurysms was high $(3 / 9,30 \%)$ in our series, there was no significant difference in the recanalization rate between the posterior and 
the anterior circulations. The reason might be because the proportion of BA aneurysms in the posterior circulation was smaller $(9 / 24,37.5 \%)$ in our series compared with that in the report of Nguyen et al, ${ }^{20}$ though they did not show the specific number of aneurysms.

Three of 19 recanalized aneurysms were retreated $>5$ years after the initial treatment. These 3 aneurysms slightly recanalized within 2 years, were stable for the next 3 years, and then recanalized deeper $>5$ years after the first treatment. Therefore, if recanalization is detected within 2 years, we should continue imaging follow-up for $>5$ years. Significant risk factors for late deterioration are uncertain, but 2 of these 3 aneurysms were large $(>14$ $\mathrm{mm}$ ). We suggest that early recanalized aneurysms should be followed up for $>5$ years, despite the extent of recanalization, especially in large aneurysms.

In our study, aneurysms stable for 2 years after the procedure were not recanalized. Raymond et $\mathrm{al}^{4}$ previously suggested that all patients should be followed up with noninvasive imaging studies for at least 3 years because $96.9 \%$ of all recanalizations were diagnosed by 3 years in their study. Furthermore, Holmin et $\mathrm{al}^{22}$ showed that stable angiographic findings during a 1-year interval predicted a low risk of recanalization. These reports are compatible with our results. If no recanalization is observed within 2 years after initial endovascular embolization for an unruptured aneurysm, further annual follow-up imaging studies in relation to treated aneurysms might be excessive. However, in the present study, development of new (de novo) aneurysms or enlargement of tiny or nontreated aneurysms coexisting with treated aneurysms was not evaluated. In managing patients with unruptured aneurysms, risk factors of growth and rupture need to be addressed. Awareness of a previous history of subarachnoid hemorrhage and risk factors, such as smoking, hypertension, and a family history, is considered important for preventing aneurysmal rupture and growth. ${ }^{23}$ Therefore, a follow-up examination after coil embolization should be performed individually while considering de novo and nontreated aneurysms.

In the present study, relatively old imaging equipment was used. Newer instruments and technology in MRA for reducing artifacts and improving accuracy may be better for determining recanalization. However, because 3 expert neurosurgeons were in agreement about the results, our method of imaging was appropriate for evaluating recanalization of aneurysms. Additionally, in our institution, noncontrast TOF-MRA is routinely used to evaluate recanalization of aneurysms. Gadolinium-based enhanced MRA might be more accurate than TOF-MRA. ${ }^{24,25}$ van Amerongen et $\mathrm{al}^{11}$ reported that the specificity of TOF-MRA was $84 \%$ with a sensitivity of $86 \%$ for discovery of aneurysm recanalization. For contrast-enhanced MRA, the specificity and sensitivity were $89 \%$ and $86 \%$, respectively. However, we do not routinely select this method at our institution because contrast-enhanced MRA is more invasive and time-consuming than noncontrast MRA. However, contrast-enhanced MRA shows a higher quality view of stented parent arteries and fewer artifacts compared with TOF. ${ }^{24,26}$

Our study has some limitations. First, although a wide neck and the volume embolization rate are correlated with recanalization, ${ }^{3,15,18,19}$ we were not able to evaluate these factors. We could not collect sufficient data on the size of the neck or the volume embolization rate for further analysis because of the retrospective design of this study. However, our result about risk factors of recanalization could be acceptable because our other results are consistent with previous reports (eg, recanalization was correlated with a larger aneurysm size in the present study)., $3,9,14,15$ Second, the mean observational span was 7 years. Earlier follow-up cases tended to be excluded because those patients had stopped coming to the hospital. Therefore, the mean follow-up period was $7.0 \pm 1.4$ years. Furthermore, whether a nonrecanalized aneurysm within 2 years after embolization will be secure for decades or a lifetime is unclear because late recanalization will probably occur in the future. Further studies on this issue for a longer period might be required. Third, this study had a retrospective design that was based on the clinical practice data. In the present study, a relatively large number of aneurysms $(n=30$, non-follow-up group) could not be followed up. Considering the relatively small sample size in this study, loss in a non-follow-up group might have affected the significance of the results. However, the distribution of the maximum size of aneurysms between the follow-up and non-follow-up groups was not significantly different (Fig 2). Therefore, we consider that our results are acceptable, even though a relatively large number of aneurysms could not be followed up. Future studies on this issue are required in prospective and large cohorts.

\section{CONCLUSIONS}

Our study shows that aneurysms in which recanalization is not observed within 2 years after endovascular coil embolization are stable during a mean follow-up of 7 years. This result may be helpful in considering the appropriate span or frequency of follow-up imaging for embolized cerebral aneurysms.

\section{ACKNOWLEDGMENTS}

We thank Ellen Knapp, PhD, from the Edanz Group (www. edanzediting.com/ac) for editing a draft of the manuscript.

Disclosures: The authors declare that there is no conflict of interest.

\section{REFERENCES}

1. Molyneux AJ, Birks J, Clarke A, et al. The durability of endovascular coiling versus neurosurgical clipping of ruptured cerebral aneurysms: 18-year follow-up of the UK cohort of the International Subarachnoid Aneurysm Trial (ISAT). Lancet 2015;385:691-97 CrossRef Medline

2. Oishi H, Yamamoto M, Shimizu T, et al. Endovascular therapy of 500 small asymptomatic unruptured intracranial aneurysms. AJNR Am J Neuroradiol 2012;33:958-64 CrossRef Medline

3. Murayama Y, Nien YL, Duckwiler G, et al. Guglielmi detachable coil embolization of cerebral aneurysms: 11 years' experience. J Neurosurg 2003;98:959-66 CrossRef Medline

4. Raymond J, Guilbert F, Weill A, et al. Long-term angiographic recurrences after selective endovascular treatment of aneurysms with detachable coils. Stroke 2003;34:1398-403 CrossRef Medline

5. Gallas S, Pasco A, Cottier JP, et al. A multicenter study of 705 ruptured intracranial aneurysms treated with Guglielmi detachable coils. AJNR Am J Neuroradiol 2005;26:1723-31 Medline

6. Geyik S, Yavuz K, Ergun O, et al. Endovascular treatment of intracranial aneurysms with bioactive Cerecyte coils: effects on treatment stability. Neuroradiology 2008;50:787-93 CrossRef Medline

7. Ries T, Siemonsen S, Thomalla G, et al. Long-term follow-up of cerebral aneurysms after endovascular therapy prediction and 
outcome of retreatment. AJNR Am J Neuroradiol 2007;28: 1755-61 CrossRef Medline

8. Renowden SA, Koumellis $\mathrm{P}$, Benes $\mathrm{V}$, et al. Retreatment of previously embolized cerebral aneurysms: the risk of further coil embolization does not negate the advantage of the initial embolization. AJNR Am J Neuroradiol 2008;29:1401-04 CrossRef Medline

9. Campi A, Ramzi N, Molyneux AJ, et al. Retreatment of ruptured cerebral aneurysms in patients randomized by coiling or clipping in the International Subarachnoid Aneurysm Trial (ISAT). Stroke 2007;38:1538-44 CrossRef Medline

10. Gallas S, Januel AC, Pasco A, et al. Long-term follow-up of $\mathbf{1 0 3 6}$ cerebral aneurysms treated by bare coils: a multicentric cohort treated between 1998 and 2003. AJNR Am J Neuroradiol 2009;30: 1986-92 CrossRef Medline

11. van Amerongen MJ, Boogaarts HD, de Vries J, et al. MRA versus DSA for follow-up of coiled intracranial aneurysms: a meta-analysis. AJNR Am J Neuroradiol 2014;35:1655-61 CrossRef Medline

12. Nihon-nousottyuu-gakkai. Nousottyuu-guidline-iinkai. Nousottyuutiryou-guidline (in Japanese). 2015. Kyouwakikaku, Tokyo; 2015;230-35

13. Roy D, Milot G, Raymond J. Endovascular treatment of unruptured aneurysms. Stroke 2001;32:1998-2004 CrossRef Medline

14. Piotin M, Spelle L, Mounayer C, et al. Intracranial aneurysms: treatment with bare platinum coils-aneurysm packing, complex coils, and angiographic recurrence. Radiology 2007;243:500-08 CrossRef Medline

15. Sluzewski M, Menovsky T, van Rooij WJ, et al. Coiling of very large or giant cerebral aneurysms: long-term clinical and serial angiographic results. AJNR Am J Neuroradiol 2003;24:257-62 Medline

16. Koyanagi M, Ishii A, Imamura H. Long-term outcomes of coil embolization of unruptured intracranial aneurysms. J Neurosurg 2018; 129:1492-98 CrossRef Medline

17. Li MH, Gao BL, Fang C, et al. Angiographic follow-up of cerebral aneurysms treated with Guglielmi detachable coils: an analysis of 162 cases with 173 aneurysms. AJNR Am J Neuroradiol 2006;27: 1107-12 Medline
18. Tamatani S, Ito Y, Abe H, et al. Evaluation of the stability of aneurysms after embolization using detachable coils: correlation between stability of aneurysms and embolized volume of aneurysms. AJNR Am J Neuroradiol 2002;23:762-67 Medline

19. Sugiyama S, Niizuma K, Sato K, et al. Blood flow into basilar tip aneurysms: a predictor for recanalization after coil embolization. Stroke 2016;47:2541-47 CrossRef Medline

20. Nguyen TN, Hoh BL, Amin-Hanjani S, et al. Comparison of ruptured vs unruptured aneurysms in recanalization after coil embolization. Surg Neurol 2007;68:19-23 CrossRef Medline

21. Bavinzski G, Talazoglu V, Killer M, et al. Gross and microscopic histopathological findings in aneurysms of the human brain treated with Guglielmi detachable coils. J Neurosurg 1999;91:284-93 CrossRef Medline

22. Holmin S, Krings T, Ozanne A, et al. Intradural saccular aneurysms treated by Guglielmi detachable bare coils at a single institution between 1993 and 2005: clinical long-term follow-up for a total of 1810 patient-years in relation to morphological treatment results. Stroke 2008;39:2288-97 CrossRef Medline

23. Sonobe M, Yamazaki T, Yonekura M, et al. Small unruptured intracranial aneurysm verification study: SUAVe study, Japan. Stroke 2010;41:1969-77 CrossRef Medline

24. Anzalone N, Scomazzoni F, Cirillo M, et al. Follow-up of coiled cerebral aneurysms at 3T: comparison of 3D time-of-flight $M R$ angiography and contrast-enhanced MR angiography. AJNR Am J Neuroradiol 2008;29:1530-36 CrossRef Medline

25. Kaufmann TJ, Huston J 3rd, Cloft HJ, et al. A prospective trial of 3T and 1.5T time-of-flight and contrast-enhanced $M R$ angiography in the follow-up of coiled intracranial aneurysms. AJNR Am J Neuroradiol 2010;31:912-18 CrossRef Medline

26. Choi JW, Roh HG, Moon WJ, et al. Time-resolved 3D contrastenhanced MRA on 3.0T: a non-invasive follow-up technique after stent-assisted coil embolization of the intracranial aneurysm. Korean J Radiol 2011;12:662-70 CrossRef Medline 